\title{
Phosphaturic Mesenchymal Tumor
}

National Cancer Institute

\section{Source}

National Cancer Institute. Phosphaturic Mesenchymal Tumor. NCI Thesaurus. Code C67237.

An extremely rare, benign or malignant mesenchymal tumor arising from the soft tissues. It is a distinctive tumor, which usually displays the following morphologic characteristics: low cellularity, myxoid changes, presence of spindled cells and osteoclasts, hemangiopericytoma-like vessels, hemorrhage, and osteoid-like matrix. It is associated with the presence of a paraneoplastic syndrome called osteogenic osteomalacia. This syndrome usually precedes the appearance of the tumor, and it is characterized by phosphaturia, hypophosphatemia, normal serum calcium levels, and decreased levels of 1,25-dihydroxyvitamin D3. Patients present with bone and muscle pain, severe muscle weakness, fractures, gait disturbances, skeletal deformity, height loss, and slow growth. The metabolic disturbances improve or completely disappear after the complete resection of the tumor. 